\title{
Water Quality in the Gaza Strip: The Present Scenario
}

\author{
Medhat Abbas $^{1}$, Maurizio Barbieri ${ }^{2 *}$, Maria Battistel ${ }^{2 *}$, Giuditta Brattini ${ }^{3}$, \\ Angelica Garone $^{2 *}$, Barbara Parisse ${ }^{2}$ \\ ${ }^{1}$ El Shifa Hospital, Ministery of Health, Gaza, Palestine \\ ${ }^{2}$ Department of Earth Science, University of Rome "Sapienza", Rome, Italy \\ "Gazzella" Onlus Association, Italy \\ Email: "'maurizio.barbieri@uniroma1.it, ${ }^{*}$ maria.battistel@uniroma1.it, ${ }^{*}$ angelica.garone@uniroma1.it
}

Received October 8, 2012; revised November 10, 2012; accepted November 18, 2012

\begin{abstract}
The Gaza Strip is one of the most densely populated areas in the world, 4505 people per $\mathrm{km}^{2}$ and the only source of water is represent by groundwater. The water quality in Gaza is very poor and the groundwater is affected by many different contaminants sources including soil/water interaction in the unsaturated zone due to recharge and return flows, mobilization of deep brines, sea water intrusion or upcoming and disposal of domestic and industrial wastes into the aquifer. Previous reports on the water quality in Gaza discussed the high levels of major ions (especially of chloride, nitrate and fluoride) in the drinking water. Moreover, little or no information is available for trace elements in the groundwater of the Gaza Strip. The sources of trace elements in groundwater could be natural and anthropogenic. 58 wells were sampled during July 2010, and were analyzed major ions and trace elements to check if the water quality is improving from the previous report. This study has revealed that no groundwater in Gaza Strip meets all WHO drinking water standards. The contaminants which affected the Gaza Strip are of different types and they originate from different sources. The environmental conditions are no safe for the population and some actions to improve the groundwater conditions are necessary to safeguard the population.
\end{abstract}

Keywords: Gaza; Drinking Water; Trace Elements; Population Safety; Food Security

\section{Introduction}

A constant monitoring of groundwater in Gaza Strip is crucial: the groundwater is the only source of water in this area. Municipal groundwater wells are currently being used for drinking and domestic purposes while private wells are being used for irrigation and its should be sampled 2 - 4 times a year for the analysis of anions, cations, trace elements and pesticides [1]. The water quality in Gaza is affected by many different water sources including soil/water interaction in the unsaturated zone due to recharge and return flows, mobilization of deep brines, sea water intrusion or upcoming and disposal of domestic and industrial wastes into the aquifer [2]. Previous reports on the water quality in Gaza [1,4] discussed the high levels of major ions (especially of chloride, nitrate and fluoride) in the drinking water. Moreover, little or no information is available for trace elements in the groundwater of the Gaza Strip. The sources of trace elements in groundwater could be natural and anthropogenic. The distribution of trace elements in groundwater is continuously reset by complex geochemical processes (e.g., equilibrium and non-equilibrium water/solid interactions,

\footnotetext{
*Corresponding authors.
}

advection, dispersion, absorption, precipitation, co-precipitation, chelation, colloidal interaction) and biological processes [3]).

This paper study the composition of the groundwater few years after the war events (2006-2008/2009) that affected years after the war events (2006-2008/2009) that affected the Gaza Strip. The results were compared to the last published studies regarding the drinkable of groundwater [1,4]. In 2002 Shomar [1] analyzed the waters of 71 municipal and 21 private wells used for drinking and domestic purposes. The results show that the $89 \%$ of water wells are not considered usable for drinking purposes, especially for the worrisome concentrations of chlorine, fluoride and nitrates that exceed the guidelines of the World Health Organization (WHO) [5]. As for trace elements results show high concentrations of zinc, lead, arsenic and cadmium.

Shomar [1] proposed interventions ranged from frequent monitoring wells and implementation of studies, on the correlation between the incidence of some diseases and pollutants, the development of a strategy for disposal of waste that would prevent contamination of groundwater.

The aim of this paper is to check the quality of stream 
water in the Gaza Strip after 2002 and identify the possible source of contaminants. Analysis of trace waters contribute to implement the knowledge of the geochemical and biological process involved the water resource of Gaza Strip, and also determine if any of trace elements threats human health in Gaza Strip.

\section{Study Area}

The Gaza Strip is one of the most densely populated areas in the world, 4505 people per $\mathrm{km}^{2}$ [6]. For administrative purposes, the area has been divided into five regions: North, Gaza, Middle, Khan Younis and Rafah, Figure 1.

Approximately $85 \%$ of the population of the Gaza Strip drinks from municipal groundwater wells and $15 \%$, mostly in agricultural areas, use private wells to supply their drinking water [4].

The study area is part of the coastal zone in a transitional area between a temperate Mediterranean climate to the east and north and an arid climate of the Negev and Sinai deserts to the east and south. As a result, the Gaza
Strip has a characteristic semi-arid climate. The aquifer system in Gaza Strip is part of the larger Palestinian coastal plain hydrogeological system, which extends from Haifa City in the north to Sinai desert in the south and over an area of about $2000 \mathrm{~km}^{2}$. The Palestinian coastal plain is characterized by flat relief, and is bounded to the east by the foothills of the West Bank mountain belt. This plain is narrow in the north and gets wider in the south. It has an average width of about $13 \mathrm{~km}$. The main aquifer formation is composed of calcareous sandstone and gravel from the Pleistocene age and recent Holocene sand dunes. Some silts, clay, and conglomerate exist in the aquifer formation. Three main clay layers intercalate the aquifer and divide it into three main sub-aquifers in the west. These clay layers extend from the shore in the west to about $3-5 \mathrm{~km}$ inland. Thus, the aquifer is mainly unconfined in the eastern part and confined/unconfined in the western part. Aquifer thickness varies from a few meters in the east of Gaza Strip to about 170 m near the shoreline. The aquifer overlies thick impermeable marine clay of the Tertiary age called the Saqaya Formation [7].

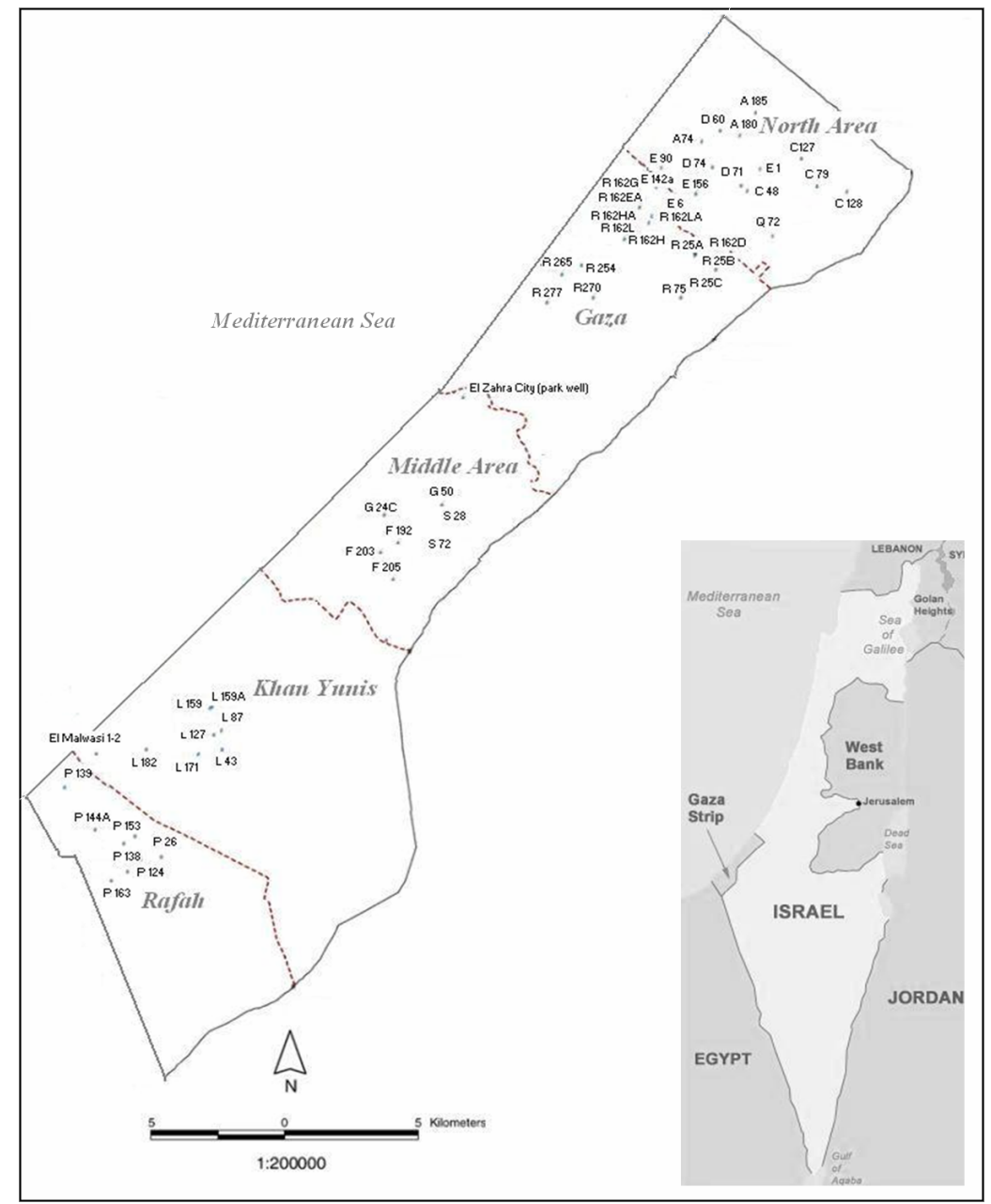

Figure 1. Five regions of the Gaza Strip and location of investigated groundwater wells. 


\section{Sampling and Analysis}

58 Municipal wells were sampled by Gazzella ONLUS during July 2010 with the permission of the Ministry of Health Gaza-Palestine, Table 1.

Gazzella ONLUS is a nonprofit Organization. The principal aim of the Association is the aid, the care and the rehabilitation of the Palestinian children injured by weapons. Mostly the Association acts through the children sponsorship.

All samples were collected in laboratory certified clean bottles and labeled as to the well depth and location, date and time of sample collection, analyses to be performed, and field preservation performed, if any [8]. The measure of water temperature, electrical conductivity and $\mathrm{pH}$ value couldn't be possible to determine in the field. Only the electrical conductivity was measured in laboratory with a multi-parameter sensor (PCTSTest 35 EUTECH INSTR-UMENTS, reliability $\pm 1 \%$ ). Bicarbonate was determined by titration with $0.1 \mathrm{~N} \mathrm{HCl}$ (reliability $\pm 2 \%$ ).

Water samples were filtered through cellulose filters $(0.45 \mu \mathrm{m})$. Each sample was divided into two subsamples: the first had stored at $4^{\circ} \mathrm{C}$ and been used to determine their major and minor constituents, with a Dionex DX-120 ion chromatograph (reliability $\pm 2 \%$ ). A Dionex CS- 12 column was used for determining cations $(\mathrm{Na}, \mathrm{K}, \mathrm{Mg}$, $\mathrm{Ca}$ ), whereas a Dionex AS9-SC column was used for anions $\left(\mathrm{F}, \mathrm{Cl}, \mathrm{NO}_{3}, \mathrm{SO}_{4}\right)$. The analytical accuracy of these methods ranged from $2 \%$ to $5 \%$. The other was transferred to clean acid-washed polyetheylene bottles and acidified with concentrated nitric acid (Ultrapur, Merck, $\mathrm{v} / \mathrm{v})$ to $\mathrm{pH}<2$ and stored at $4^{\circ} \mathrm{C}$ until analyses by inductively coupled plasma mass spectrometry, ICP-MS, reliability $\pm 2 \%$ ).

The analysis was carried out at the Geochemistry Laboratory of Sapienza University of Rome.

\section{Results}

In this session will only discuss the most environmentally significant data and those that exceed the WHO standards that pose risk for human or environmental health. The values of each well were averaged to provide the figures in this section. Our results were compared to the last published study about the groundwater of Gaza strip [1]. Tables 2 and 3 summarized the measured variables, minimum and maximum value, standard deviations, average and median found in the wells of the five regions of Gaza Strip.

Table 1. Wells sampled during July 2010 in Gaza Strip. C48, G24C and P26 are agricultural wells; S28 is both agricultural and civilian. The other wells are civilian.

\begin{tabular}{|c|c|c|c|c|c|c|c|c|}
\hline Region & No & Well number & Region & No & Well number & Region & No & Well number \\
\hline \multirow[t]{14}{*}{ North area } & 1 & A185 & Gaza & 20 & R162L & Middle area & 39 & S28 \\
\hline & 2 & A180 & & 21 & R162LA & Rafah & 40 & New well 2009 El Zoherat \\
\hline & 3 & $\mathrm{C} 79$ & & 22 & R162D & & 41 & P124 \\
\hline & 4 & $\mathrm{C} 128$ & & 23 & R162EA & & 42 & P139 \\
\hline & 5 & $\mathrm{C} 48$ & & 24 & R277 & & 43 & P26 \\
\hline & 6 & $\mathrm{C} 127$ & & 25 & R254 & & 44 & P153 \\
\hline & 7 & E1 & & 26 & R265 & & 45 & P144A \\
\hline & 8 & Q72 & & 27 & R270 & & 46 & P138 \\
\hline & 9 & E156 & & 28 & R75 & & 47 & P163 \\
\hline & 10 & D2 & & 29 & $\mathrm{R} 25 \mathrm{~A}$ & & 48 & El Safa \\
\hline & 11 & D60 & & 30 & $\mathrm{R} 25 \mathrm{~B}$ & Khan Yunis & 49 & L176 \\
\hline & 12 & E90 & & 31 & $\mathrm{R} 25 \mathrm{C}$ & & 50 & L182 \\
\hline & 13 & D71 & Middle area & 32 & $\mathrm{G} 24 \mathrm{C}$ & & 51 & L127 \\
\hline & 14 & D74 & & 33 & G50 & & 52 & L43 \\
\hline \multirow[t]{5}{*}{ Gaza } & 15 & E142a & & 34 & El Zahra City (Park Well) & & 53 & L87 \\
\hline & 16 & E6 & & 35 & F203 & & 54 & L159 \\
\hline & 17 & $\mathrm{R} 162 \mathrm{H}$ & & 36 & F192 & & 55 & L159A \\
\hline & 18 & R162HA & & 37 & F205 & & 56 & El Mawasi1 \\
\hline & 19 & $\mathrm{R} 162 \mathrm{G}$ & & 38 & S72 & & 58 & El Mawasi2 \\
\hline
\end{tabular}




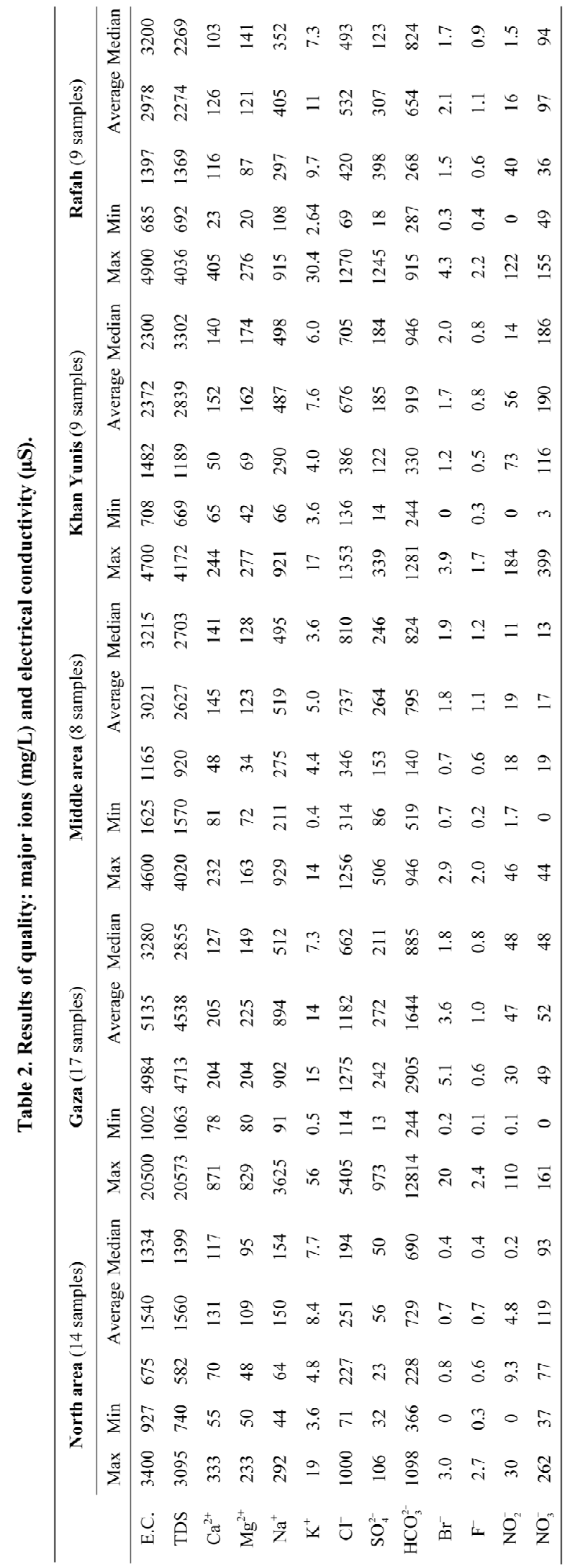

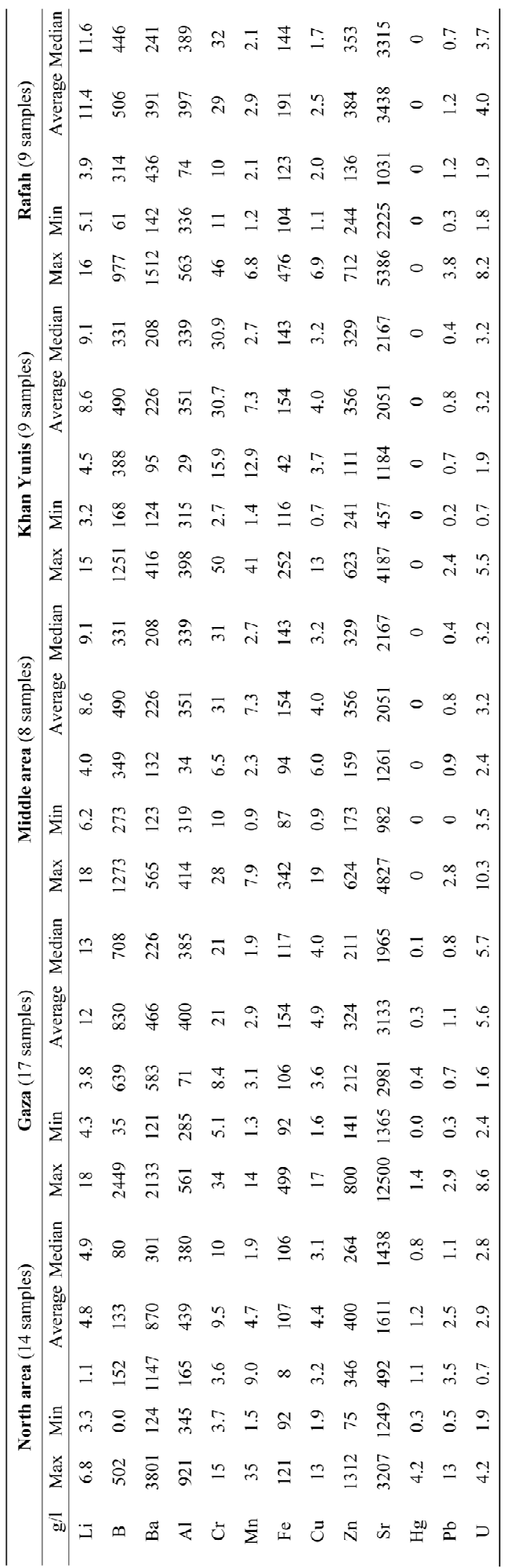




\subsection{General Physical-Chemical Parameters}

Figure 2 shows the values of TDS in five region of the Gaza strip for each wells monitored during 2010. The lowest average values of TDS were measured in the North area $(1560 \mathrm{mg} / \mathrm{L})$, while the highest average value of TDS were estimated in Gaza area, $4538 \mathrm{mg} / \mathrm{L}$, Table 1. This is in agreement with the findings of Shomar [1] about the general trend of TDS, but the values we measured in 2010 appear to be higher than those measured by Shomar [1]. Except for a few wells distributed in Gaza strip, the majority of wells exceed the WHO standards for TDS $(1000 \mathrm{mg} / \mathrm{L})$. R162D, situated in Gaza city, is the well is one in which has the highest level, more than $20,000 \mathrm{mg} / \mathrm{L}$.

\subsection{Major Anions and Cations}

Except for a few wells in North Area region, all wells sampled showed high to very high concentration of the major ions, Table 2. The Piper diagram, Figure 3, shows that the wells' groundwater fall into two different idrogeochemical facies: North area has $\mathrm{Ca}-\mathrm{HCO}_{3}$ waters typical of shallow fresh groundwater and the other region have sodium-chlorine waters indicating that the Gaza Strip aquifer suffer a mixing between fresh water and seawater.

The $60 \%$ of the wells sampled showed nitrate levels above the WHO standard of $50 \mathrm{mg} / \mathrm{L}$, Table 4 and Figure 4. The average concentrations of $\mathrm{NO}_{3}$ are 189, 118, 97, 52 and 17 in the Khan Yunis, North area, Rafah,

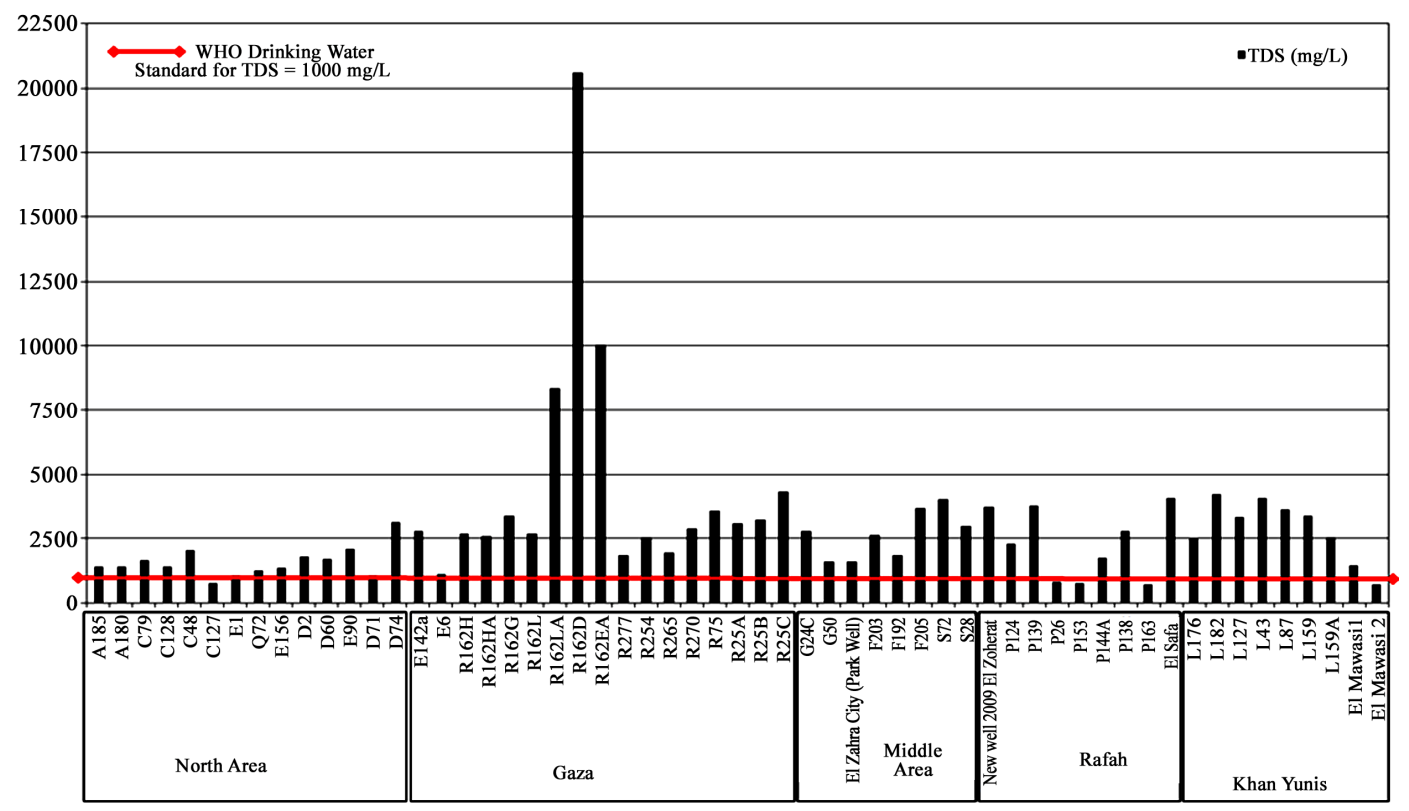

Figure 2. Variation of TDS concentrations in the groundwater wells of the Gaza Strip.

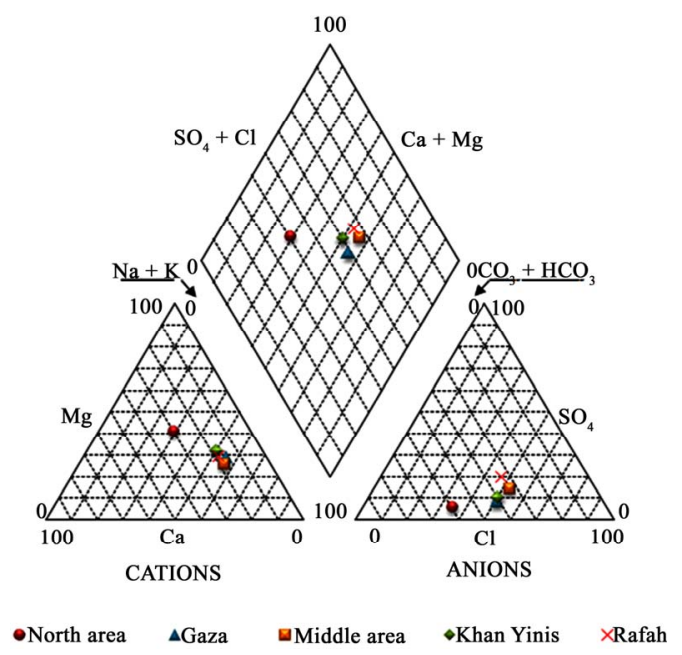

Figure 3. Piper plot showing the average composition of Gaza Strip groundwater.
Table 4. Percentage of wells which has major ions above WHO standards. Comparison between 2010 and 2002.

\begin{tabular}{cccc}
\hline \multirow{2}{*}{ Parameter } & WHO $(\mathrm{mg} / \mathrm{l})$ & \multicolumn{2}{c}{ Above WHO (\%) } \\
\cline { 3 - 4 } & & 2010 & $2002^{\mathrm{a}}$ \\
\hline $\mathrm{TDS}$ & 1000 & 88 & 63 \\
$\mathrm{Na}$ & 200 & 67 & 53 \\
$\mathrm{Cl}$ & 250 & 71 & 54 \\
$\mathrm{SO}_{4}$ & 250 & 28 & 14 \\
$\mathrm{~F}$ & 1.05 & 17 & 20 \\
$\mathrm{NO}_{2}$ & 3 & 59 & n.a. \\
$\mathrm{NO}_{3}$ & 50 & 60 & 90 \\
\hline
\end{tabular}

${ }^{\mathrm{a} S h o m a r} 2006[1]$. 


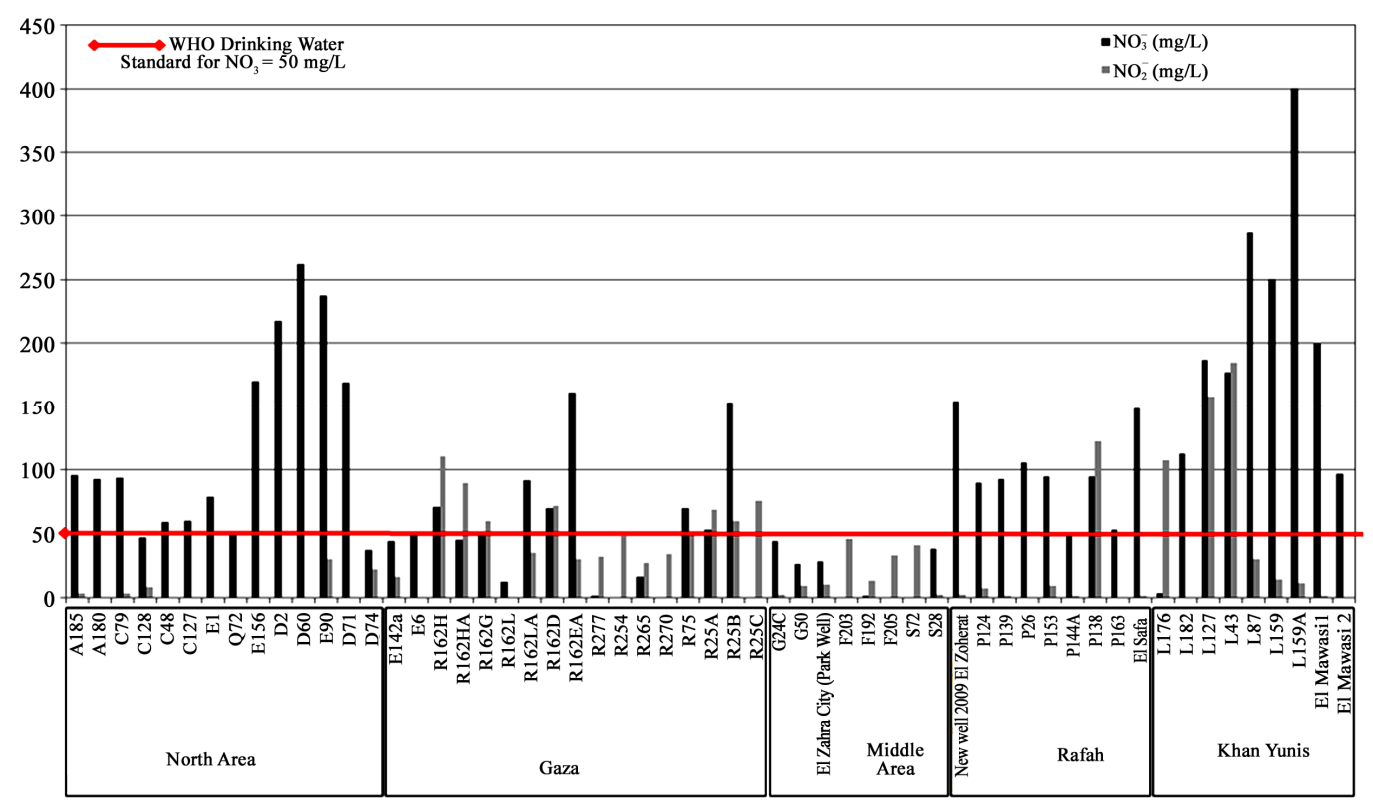

Figure 4. Variation of $\mathrm{NO}_{3}$ and $\mathrm{NO}_{2}$ concentrations in the groundwater wells of the Gaza Strip.

Gaza and the Middle area, respectively. Some of wells situated in Khan Yunis, Rafah and North area the concentrations of nitrate can exceed for 3 - 9 times the WHO standard. However the percentage of wells which exceed the WHO standards for nitrate decreased compared to 2002, Table 4. Nitrite average concentrations in the Gaza aquifer ranged from 4.8 until $56 \mathrm{mg} / \mathrm{L}$. The results stress a concentration above the WHO standards in some wells of Gaza, Rafah and Khan Yunis. The lowest average values of chlorine were measured in North area (251 $\mathrm{mg} / \mathrm{L}$ ), while the highest average values were estimated in Gaza $(1182 \mathrm{mg} / \mathrm{L})$. The trend of this data is in agreement with the previous data. The maximum value of chlorine was measured in Gaza and it was $5405 \mathrm{mg} / \mathrm{L}$; so, the minimum value of this one was estimated in Rafah and it was $69 \mathrm{mg} / \mathrm{L}$. The $71 \%$ of the wells sampled showed chlorine levels above the WHO standard of 250 $\mathrm{mg} / \mathrm{L}$, Table 4 and Figure 5. However the percentage of wells which exceed the WHO standards for chlorine increased compared to 2002, Table 4.

The average concentration of fluoride in the groundwater in the Gaza Strip is no higher than the WHO standard $(1.5 \mathrm{mg} / \mathrm{L})$. Only the $17 \%$ of the wells monitored showed fluoride concentration above the WHO standard of $1.5 \mathrm{mg} / \mathrm{L}$. The percentage of wells which exceed the WHO standards for fluoride decreased compared to 2002, Table 4 and Figure 6 The most affected zones are Middle area $(1.1 \mathrm{mg} / \mathrm{L})$ and $\operatorname{Rafah}(1.1 \mathrm{mg} / \mathrm{L})$. So, the maximum value of fluoride was measured in North area and it was $2.7 \mathrm{mg} / \mathrm{L}$; the minimum value of this one was estimated in Gaza and it was $0.1 \mathrm{mg} / \mathrm{L}$. The highest average values of $\mathrm{SO}_{4}$ were in Rafah $(307 \mathrm{mg} / \mathrm{L})$, while the lowest average values were in North area $(56 \mathrm{mg} / \mathrm{L})$. So, the most of the wells in north area had $\mathrm{SO}_{4}$ levels less than the WHO standard $(250 \mathrm{mg} / \mathrm{L})$. The $28 \%$ of the wells monitored showed sulfates concentration above the WHO standard. The percentage of wells which exceed the WHO standards for sulfates doubled compared to 2002, Table 4.

The lowest average values of $\mathrm{Na}$ were found in the north $(150 \mathrm{mg} / \mathrm{L})$ and the highest average values of this one were in the region of Gaza $(894 \mathrm{mg} / \mathrm{L})$. The $67 \%$ of the wells monitored showed sodium levels above the WHO standard of $200 \mathrm{mg} / \mathrm{L}$, Table 4 and Figure 5. So, the maximum value of sodium was measured in Gaza and it was $3625 \mathrm{mg} / \mathrm{L}$; the minimum value of this one was estimated in North area and it was $44 \mathrm{mg} / \mathrm{L}$.

Most of wells analyzed for $\mathrm{K}$ showed the average value more than $5 \mathrm{mg} / \mathrm{l}$. The highest average value of $\mathrm{K}$ was measured in Gaza $(14 \mathrm{mg} / \mathrm{L})$, followed by the average value of $\mathrm{K}$ in Rafah. The minimum value of $\mathrm{K}$ was estimated in Middle area and it was $0.4 \mathrm{mg} / \mathrm{L}$.

The Rafah wells showed the lowest average values of calcium $(126 \mathrm{mg} / \mathrm{L})$, while the region of Gaza well had the highest average value of $\mathrm{Ca}(205 \mathrm{mg} / \mathrm{L})$. The North area wells showed the lowest average values of Mg (109 $\mathrm{mg} / \mathrm{L}$ ), while the region of Gaza well had the highest average value of $\mathrm{Mg}(225 \mathrm{mg} / \mathrm{L})$.

\subsection{Trace Elements}

Table 3 shows the results of trace elements and summarized the measured variables, minimum and maximum value, standard deviations, average and median found in the wells of the five regions of Gaza Strip. Table 5, instead, shows the percentage of wells which have trace elements above WHO standards, during 2010. 


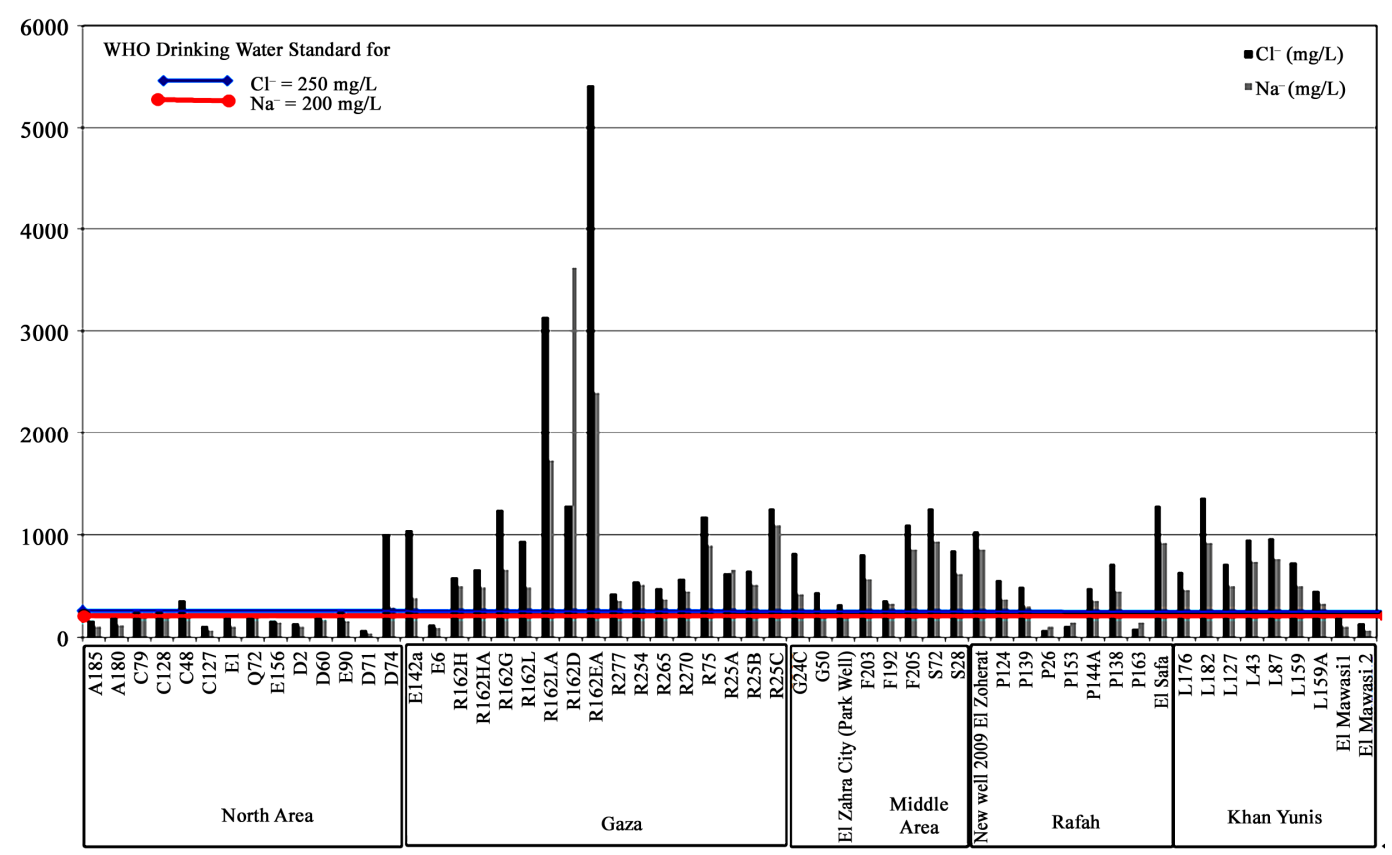

Figure 5. Variation of $\mathrm{Cl}^{-}$and $\mathrm{Na}^{-}$concentrations in the groundwater wells of the Gaza Strip.

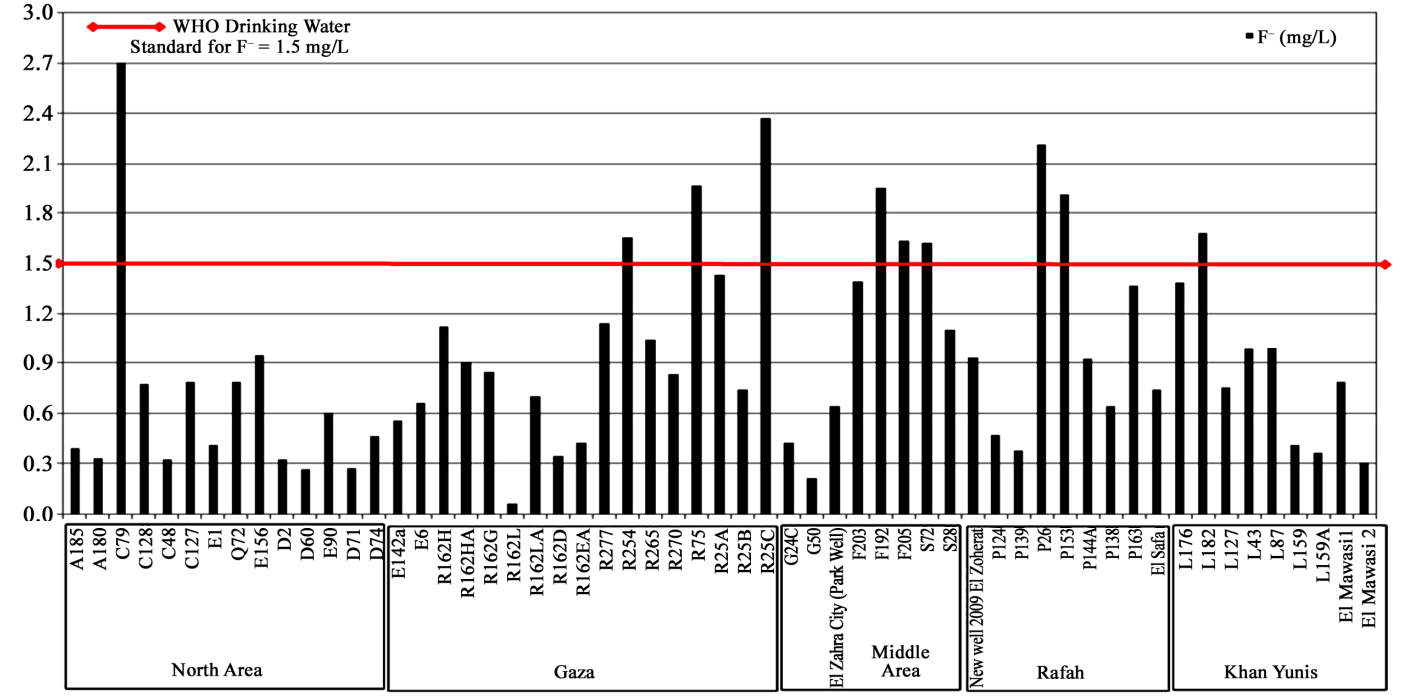

Figure 6. Variation of F-concentrations in the groundwater wells of the Gaza Strip.

Table 5. Percentage of wells which have trace elements above WHO standards, during 2010.

\begin{tabular}{ccc}
\hline Parameter $(\mu \mathrm{g} / \mathrm{l})$ & WHO & Above WHO $(\%)^{\mathrm{b}}$ \\
\hline $\mathrm{Al}$ & 200 & 100 \\
$\mathrm{~B}$ & 500 & 41.4 \\
$\mathrm{Cr}$ & 50 & 1.7 \\
$\mathrm{Fe}$ & 300 & 8.6 \\
$\mathrm{Hg}$ & 1 & 12.1 \\
$\mathrm{~Pb}$ & 10 & 1.7 \\
\hline
\end{tabular}

${ }^{\mathrm{b} W H O} 2010$ [6].
The most striking case concerns the concentration of aluminum in 2010 compared with that measured by Shomar in 2002. Our results show that $100 \%$ of the wells sampled have a higher concentration of aluminum to the WHO standard of $200 \mu \mathrm{g} / \mathrm{L}$, Table 5 . The lowest average values of $\mathrm{Al}$ were measured in Middle area and in Khan Yunis (both with $351 \mu \mathrm{g} / \mathrm{L}$ ), while the highest average values were estimated in North area $(439 \mu \mathrm{g} / \mathrm{L})$ this one was estimated in the same area and it was $2.7 \mu \mathrm{g} / \mathrm{L}$, Table 3. The maximum value of $\mathrm{Al}$ was measured in North area and it was $921 \mu \mathrm{g} / \mathrm{L}$; the minimum value of this one was estimated in Gaza and it was $285 \mu \mathrm{g} / \mathrm{L}$. It is clear that from 2002 to 2010 aluminum in groundwater of the 
Strip has increased compared to 2002. Also the concentration of $\mathrm{Hg}$ measured by Shomar in 2002 shows very low values. In 2010 , the $12.1 \%$ of the wells monitored showed mercury levels above the WHO standard of 1 $\mu \mathrm{g} / \mathrm{L}$, Table 5 . $\mathrm{Hg}$ concentrations averaged 0.3 to 1.2 $\mu \mathrm{g} / \mathrm{L}$. The maximum value of $\mathrm{Hg}$ was measured in North area and it was $4.2 \mu \mathrm{g} / \mathrm{L}$; the minimum value of this one was estimated in Gaza and it was $1.4 \mu \mathrm{g} / \mathrm{L}$.

In Middle area, Khan Yunis and Rafah, $\mathrm{Hg}$ was not found in any of the sampled wells.

Generally, the Fe concentration were lower than the WHO standard $(300 \mu \mathrm{g} / \mathrm{L})$ and only the $8.6 \%$ of the wells monitored showed Fe levels above the WHO standard, Table 5. Fe concentrations averaged 107 to 191 $\mu \mathrm{g} / \mathrm{L}$. The maximum value of Fe was measured in Gaza and it was $499 \mu \mathrm{g} / \mathrm{L}$; the minimum value of this one was estimated in Middle area and it was $87 \mu \mathrm{g} / \mathrm{L}$, Table 3. So, the $1.7 \%$ of the wells monitored showed both $\mathrm{Cr}$ and $\mathrm{Pb}$ levels above the WHO standard of 50 and $10 \mu \mathrm{g} / \mathrm{L}$, respectively, Table 5. The average concentration of $\mathrm{Cr}$ in the southern area of Gaza Strip (Khan Yunis and Rafah) was higher than those of the northern area and these data are in agreement with the previous data presented. However, the average concentration of chromium in 2010 decreased slightly compared to 2002 . The maximum value of $\mathrm{Cr}$ was measured in Khan Yunis $(50 \mu \mathrm{g} / \mathrm{L})$; the minimum value of $\mathrm{Pb}$ concentrations averaged 0.8 to $2.5 \mu \mathrm{g} / \mathrm{L}$ then most of the wells had Pb less than WHO standard $(10 \mu \mathrm{g} / \mathrm{L})$. The maximum value of $\mathrm{Pb}$ was measured in North area and it was $13 \mu \mathrm{g} / \mathrm{L}$; the minimum value of this one was estimated in Khan Yunis $(0.2 \mu \mathrm{g} / \mathrm{L})$, Table 3.

All wells had Ba less the WHO standard $(700 \mu \mathrm{g} / \mathrm{L})$ except in the North area where its average concentration corresponds to $870 \mu \mathrm{g} / \mathrm{L}$.

The results about the other trace elements are not discussed in this session because they do not exceed the WHO standard and are not dangerous to human health.

\section{Discussion}

The Gaza Strip is one of the most densely populated in the world: 4505 inhabitants per $\mathrm{km}^{2}$, with a growth rate of around 3\% [9]. Over $90 \%$ of the population benefits of drinking water supplied from municipal water mains while the remaining $10 \%$ of the population lives in rural area and uses private wells. The exploitation of groundwater is expected to grow and it is therefore necessary to develop an appropriate management plan, primarily to prevent further deterioration of an already impaired water resource, but also in an attempt to improve the current state.

More than $50 \%$ of wells sampled showed $\mathrm{Na}$ levels higher than WHO standard $(200 \mathrm{mg} / \mathrm{L})$. Groundwater of most areas is hard and this could indicate the origin and geochemical characteristics of the groundwater system in
Gaza. The aquifer is composed mainly of sand, sandstone and conglomerate strata of Pleistocene age [1]. Also the proximity of wells to the coastline makes the Gaza aquifer is impacted by contaminants from seawater intrusion. Sodium has the same trend of chlorine. The wells near the coastline in Gaza region (R162LA, R162D, R162EA) are affected by seawater, than they have high values of E.C. (respectively 9910, 20500, $13450 \mu \mathrm{S}$ ), TDS, Figure 2, $\mathrm{Na}$ and $\mathrm{Cl}$, Figure 3, and Bromine (respectively 8.6, $20,11 \mathrm{mg} / \mathrm{L})$. One of the problems affecting the population of the Gaza Strip is dental fluorosis [10]. The sources of fluorides in the groundwater of Gaza Strip are believed to be natural bedrock that supplies the fluoride ions to the water. Maybe, there are other factors to be involved in the development of dental fluorosis. These factors revolve around the intake of fluoride from dietary sources such as the consumption of fish and tea [10]. This study shows that the $17 \%$ of wells are contaminated by high concentrations of fluoride, favoring the occurrence of health problems associated with fluoride.

According to this study the $60 \%$ of the wells analyzed exceeded the WHO standards as regard nitrate.

Nitrate in contaminated water is known to cause methemoglobinemia in infants [11]. The association of diarrhea and acidosis with methemoglobinemia is more common than previously thought and can produce dangerously high methemoglobin levels [12-15]. Shomar [16] proposed that the excess $\mathrm{NO}_{3}$ in the groundwater of the Gaza Strip occurred as a results of $\mathrm{NO}_{3}$ leaching from irrigation, wastewater septic tanks, sewage sludge, animal manure and synthetic fertilizers. Moreover the high values of nitrites in Gaza area, Khan Yunis and Rafah suggest that the source of nitrogenous compounds contamination is near the wells, so the nitrite didn't yet undergo the oxidation process.

The findings of this study show that the $100 \%$ of wells exceeded the WHO standards regarding aluminum concentrations. The results of the only published study about trace elements in the Gaza Strip [1] reported that all the wells monitored during 2002 had an aluminum concentration below the WHO standards. As well as $\mathrm{Hg}$ and $\mathrm{Ba}$ where found to be less than the WHO standard during the monitoring reported by Shomar in 2002. This study detects that $41.4 \%$ and $8.6 \%$ of the 58 wells sampled in 2010 has a concentrations of respectively $\mathrm{B}$ and $\mathrm{Hg}$ higher than the WHO standards. Besides many of the agricultural wells have openings large surface area (greater than $1 \mathrm{~m}$ ), where petroleum products, fertilizers, or any other substance can easily contaminate the aquifer, through carelessness or accident. In general, the greatest threat to the aquifer from these wells appear to be petroleum products or pesticides, since both of these products tend to be stored in well construction or during the application of pesticides, farmers spray, eat and smoke, disregarding 
the general spraying instructions [1]. This study has revealed that the state of contamination of the Gaza Strip, despite the recommendations of Shomar, has not improved. Between trace elements there is also a high concentration of boron related to states of pollution due to civil and industrial discharges. Chlorine, fluoride, nitrite and nitrate are still above the limits set by WHO at times showing a decline compared to the analyses conducted in 2002 by Shomar. It is well known that the presence of metal particles is able to enter, in soluble form in the natural environment, as soil and water.

The toxicity of mercury $(\mathrm{Hg})$ has been linked to serious reactions that occur in the central nervous system and during fetal development [17]. Aluminum (Al) accumulates in the brain, kidneys, lungs, thyroid, liver, bones and intestines is recognized as a potentially harmful metal fetotoxic. Aluminum (Al) has been the most intensively studied neurotoxic substance [18]. Lead can cause kidney damage and nervous system impairment. The population of the Gaza Strip who lives in precarious conditions, in direct contact with soil/water/air, is exposed at risk of coming into contact with poisonous substances through the skin, respiratory and through food (agricultural products). Drinking water is one of the major sources of human exposure to lead $[19,20]$. Lead particularly targets the nervous system, blood and kidney [19] distal motor neuropathy and possibly seizures and coma [21]. Infants and small children are more sensitive to the effects of lead, which moreover is transported through the placenta to the fetus [22].

Lead accumulation in fetuses and small children might cause developmental disruption in terms of neurological impairment characterized by a decrease of cognitive faculties, which can be reversible or not, evaluated by psychomotor tests such as the verbal IQ (Intellectual Quotient) test [23]. The period when IQ is most affected is from birth to/about 4 years of age [24] Health effects of metal contamination, even at low levels, are only beginning to understand and study their effects. For that it is needed to pay attention to the data presented in this study demonstrate that the risk from exposure to toxins and pollutants that can cause cancer and reproductive problems, but specially can have serious consequences on children.

\section{Conclusions}

This study has revealed that the state of contamination of the Gaza Strip, despite the recommendations of Shomar [1], has not improved. No groundwater in Gaza Strip meets all WHO drinking water standards. The contaminants which affected the Gaza Strip are of various kind and they originate from different sources.

The percentage of wells which present concentrations of chlorine and sodium above the WHO standards has increased from 2002 to 2010, Table 4, in Gaza Strip. The aquifer is contaminated and not recharging adequately. The coastal aquifer is the main source of drinking water and seawater intrusion in the coastal aquifer is still a problem for the population health.

Pesticides and fertilizers are one of the main sources of contaminations. Pesticides compositions and their excessive use contaminated the groundwater with nitrate, nitrite, chlorine and trace elements. Despite high level of $\mathrm{Al}$ in all wells analysed could be due to the large use of pesticides, several studies should be conducted to find other possible sources (of $\mathrm{Al}$ and the other trace metals) and minimize the health risk assessment.

Some actions should carry out on several fronts:

- Groundwater constant monitoring which integrated the analysis of biological, organics and inorganic contaminants;

- Wastewater and solid waste management;

- Setting up a management system for use of pesticides and fertilizers through safe storage and safe application training;

- Proper maintenance and cleaning of the areas surrounding the wells;

- Management of groundwater withdrawal in the areas vulnerable seawater intrusion.

Searching for an alternative resource of water is one of the primarily action which should be carry out.

Meanwhile private tube water filter or drinkable water point of distribution could be a short term solution.

To reduce the over exploitation of groundwater the rain water should be collected and used for agricultural purpose

It is necessary to keep in mind that the armed attacks cause environmental contamination [25].

We keep still little into consideration the fact that the attacks with no-conventional weapons have an impact on the environmental and consequently on the population with devastating consequences on the health and reproduction, even and especially in the long term.

Some of the initiatives are extremely important to safeguard the population:

a) Develop the knowledge to counteract the long-term effects of such attacks by deploying structures for risk of attacks on people's health and reproduction. Therefore operate for an inquiry on the risk of exposure to genotoxic materials of war.

b) Assumption of responsibility for the scientific community to continue to investigate the nature of the weapons used to understand how to treat the victims and the effects of environmental contamination.

\section{Acknowledgements}

Thanks for the collaboration to Ayman Elramlawi M.o.H. Water Control Department and to the Organisation Pal- 
estinian Medial Relief Society-Gaza Palestine.

\section{REFERENCES}

[1] B. Shomar, "Groundwater of the Gaza Strip: Is It Drinkable?" Environmental Geology, Vol. 50, No. 5, 2006, pp. 743-751. doi:10.1007/s00254-006-0246-9

[2] S. Ghabayen, M. S. McKee and M. Kemblowski, "Ionic and Isotopic Ratios for Identification of Salinity Sources and Missing Data in the Gaza Aquifer," Journal of Hydrology, Vol. 318, No. 1-4, 2006, pp. 360-373. doi:10.1016/j.bbr.2011.03.031

[3] W. D. Newcomb and J. D. Rimstidt, "Trace Element Distribution in US Groundwaters: A Probabilistic Assessment Using Public Domain Data," Applied Geochemistry, Vol. 17, No. 1, 2002, pp. 49-57. doi: 10.1016/S0883-2927(01)00089-0

[4] B. Shomar, A. Yahya and G. Müller, "Potential Use of Treated Wastewater and Sludge in the Agricultural Sector of the Gaza Strip," Technologies and Environmental Policy, Vol. 6, No. 2, 2004, pp. 128-137. doi:10.1007/s10098-003-0228-5

[5] WHO, "Guidelines for Drinking-Water Quality," 2010. http://www.WHO.int

[6] PCBS, "Population, Housing and Establishment Census 2012," Palestinian National Authority, Palestinian Central Bureau of Statistics, Ramallah, 2012.

[7] Metcalf and Eddy, "Costal Aquifer Management Program," Final Report: Modeling of Gaza Strip Aquifer, US Agency for International Development (USAID) and Palestinian Water Authority (PWA), Gaza, 2000.

[8] APHA, "Standard Methods for the Examination of Water and Wastewater," 19th Edition, American Public Health Association, Washington DC, 1995.

[9] Central Intelligence Agency, "The World Fact Book," 2012. http://www.CIA.gov

[10] B. Shomar, G. Muller, A. Yahya, S. Askar and R. Sansur, "Fluorides in Groundwater, Soil and Infused Black Tea and the Occurrence of Dental Fluorosis among School Children of the Gaza Strip," Journal of Water and Health, Vol. 2, No. 1, 2003, pp. 23-35.

[11] A. Avery, "Infantile Methemoglobinemia: Reexamining the Role of Drinking Water Nitrates," Environmental Health Perspectives, Vol. 107, No. 7, 1999, pp. 583-586.

[12] T. Lebby, J. Roco and E. Arcinue, "Infantile Methemoglobinemia Associated with Acute Diarrheal Illness," American Journal of Emergency Medicine, Vol. 11, No. 5, 1993, pp. 471-472. doi:10.1016/j.bbr.2011.03.031

[13] A. Avery, "Cause of Methemoglobinemia: Illness versus Nitrate Exposure," Environmental Health Perspectives, Vol. 109, No. 1, 2001, pp. A12-A14.

[14] R. J. Freishtat, J. M. Chamberlain, C. M. S. Johns, S. J. Teach, C. Ronzio, M. M. Murphy-Smith and N. Gor, "A Cross-Sectional ED Survey of Infantile Subclinical Methemoglobinemia," American Journal of Emergency Medi- cine, Vol. 23, No. 4, 2005, pp. 574-576. doi:10.1016/j.ajem.2004.12.008

[15] R. Venkateswari, R. Ganesh, M. Deenadayalan, E. Mahender, B. Ramachandran and L. Janakiraman, "Transient Methemoglobinemia in an Infant," The Indian Journal of Pediatrics, Vol. 74, No. 11, 2007, pp. 1037-1038. doi:10.1007/s12098-007-0192-x

[16] B. Shomar, K. Osenbrückb and A. Yahyaa, "Elevated Nitrate Levels in the Groundwater of the Gaza Strip: Distribution and Sources," Science of the Total Environment, Vol. 398, No. 1-3, 2008, pp. 164-174. doi:10.1016/j.scitotenv.2008.02.054

[17] M. E. Crespo-López, G. L. Macêdo, S. I. D. Pereira, G. P. F. Arrifano, D. L. W. Picanço-Dinizc, J. L. M. do Nascimento and A. M. Herculano, "Mercury an Human Genotoxicity: Critical Considerations and Possible Molecular Mechanisms," Pharmacological Research, Vol. 60, No. 4, 2009, pp. 212-220. doi:10.1016/j.phrs.2009.02.011

[18] G. F. Craun, "Review of Epidemiologic Studies of Aluminium and Neurologic Disorders," Environmental Geochemistry and Health, Vol. 12, No. 1-2, 1990, pp. 125135. doi:10.1007/BF01734062

[19] INERIS (Institut National de l'Environnement Industriel et des Risques), "Plomb et ses Dérivés, in Fiche de Données Toxicologiques et Environnementales des Substances Chimiques," INERIS, Paris, pp. 1-90.

[20] R. Fertmann, S. Hentschel, D. Dengler, U. Jan and A. Lommel, "Lead Exposure by Drinking Water: An Epidemiological Study in Hamburg," International Journal of Hygiene and Environmental Health, Vol. 207, No. 3, 2004, pp. 235-244. doi:10.1078/1438-4639-00285

[21] M. Robson, "Methodologies for Assessing Exposures to Metals: Human Host Factors," Ecotoxicology and Environmental Safety, Vol. 56, No. 1, 2003, pp. 104-109. doi:10.1016/S0147-6513(03)00054-X

[22] R. Cleymaet, K. Collys, D. H. Retief, Y. Michotte, D. Slop, E. Taghon, W. Maex and D. Coomans, "Relation between Lead in Surface Tooth Enamel, Blood, and Saliva from Children Residing in the Vicinity of a Non Ferrous Metal Plant in Belgium," British Journal of Industrial Medicine, Vol. 48, No. 10, 1991, pp. 702-709. doi:10.1136/oem.48.10.702

[23] Académie des Sciences, "Contamination des Sols par les Éléments Traces: Les Risques et Leur Gestion,” Rapport No. 42, Lavoisier Tec\&Doc, Paris, 1998, p. 440.

[24] G. C. M. Watt, A. Britton, H. G. Gilmour, M. R. Moore, G. D. Murray and S. J. Robertson, "Public Health Implications of New Guidelines of Lead in Drinking Water: A Case Study in an Area with Historically High Water Lead Levels," Food and Chemical Toxicology, Vol. 38, No.1, 2000, pp. 573-579.

[25] UNEP, "Protecting the Environment during Armed Conflict an Inventory and Analysis of International Law," United Nations Environment Programme, 2009. http://www.unep.org 